\title{
Priority areas for surveillance and prevention of avian influenza during the water-bird migration season in Pakistan
}

\author{
Tariq Abbas, Hendrik Wilking, Christoph Staubach, Mario Ziller, Franz Josef Conraths \\ Institute of Epidemiology, Friedrich-Loeffler-Institut, Federal Research Institute for Animal Health, Seestrasse \\ 55, D-16868, Wusterhausen, Germany
}

\begin{abstract}
Avian influenza viruses may be introduced into domestic poultry through migratory wild birds, particularly from Pakistan, which is situated across the migratory Indus flyway and holds more than 225 wetlands. To answer the question which areas should be given priority in surveillance and prevention with respect to notifiable avian influenza during the migratory season, a subset of Asian waterbird census data was reviewed. The dataset contains 535 local sites and available counts of waterbirds reported from 1987 to 2007 . However, as the majority of the sites are not counted regularly gaps in data matrix appeared. The coordinates of 270 known sites completely fitted the administrative boundaries of the country. These coordinates were geo-processed with polygons of water-bodies and a raster map of predicted poultry density. Pixels representing the estimated number of poultry per $\mathrm{km}^{2}$ were found within a 3 to $9 \mathrm{~km}$ range of the census sites (or water-bodies) in their proximity. The coordinates were also used to map the maximum reported counts of waterbirds and local clusters of under-sampled sites. A retrospective case-series analysis of previous outbreaks (2006-2008) of influenza A virus, subtype $\mathrm{H} 5 \mathrm{~N} 1$ was performed, which revealed that $64 \%$ of outbreaks, reported to Office International des Epizooties, the World Organization for Animal Health, occurred during the migratory period. This paper highlights the potential use and limitations of the Asian waterbirds census data in the context of avian influenza. The proposed methodology may be used to prioritize districts for surveillance and economize prevention measures provided better data are generated in future.
\end{abstract}

Keywords: avian influenza, wetlands, wild migratory birds, poultry, clusters, Pakistan.

\section{Introduction}

Pakistan is located in South Asia between latitudes $24^{\circ}$ and $37^{\circ}$ North and longitudes $61^{\circ}$ and $75^{\circ}$ East. The country consists of the five provinces Punjab, Sindh, Baluchistan, Khyber Pakhtunkhwa, GilgitBaltistan plus Federally Administrated Tribal Areas. The provinces are subdivided into districts, which in turn are composed of "tehsils" (aka "talukas").

Avian influenza was never reported in Pakistan during 1963-1993, the period during which the commercial poultry sector flourished from a single farm in Karachi to a fully fledged industry (NARC, 2009). There are no published reports, however, on active monitoring efforts for this period. In December 1994, an outbreak due to avian influenza virus (AIV) of subtype H7N3 occurred in Salgran, an isolated, mountainous poultry rearing region $25 \mathrm{~km}$ north of the capital city Islamabad (Naeem and Hussain, 1995). It was followed by the emergence of H9N2 in 1998 (Naeem

Corresponding author:

Tariq Abbas

Department of Epidemiology and Public Health

University of Veterinary and Animal Sciences

Syed Abdul Qadir Jillani (Out Fall) Road, Lahore - Pakistan

Tel: 92-42-9921-1374

Email: tariq_uvas@hotmail.com et al., 1999) and another outbreak of H7N3 during 2000-2001 (Naeem and Siddique, 2006). Between 2003-2004, an extensive outbreak of H7N3 struck the southern coastal region of the country where more than $70 \%$ of the total commercial layer flocks were reared (Naeem et al., 2007). Phylogenetic analysis of local H7N3 isolates revealed that there were two introductions of $\mathrm{H} 7$ and one $\mathrm{N} 3$ introduction (Abbas et al., 2010). Only one of the $\mathrm{H} 7$ introductions became established in the poultry population, while the other was isolated from two separate outbreaks 6 years apart. The authors also showed re-assortment between the H7N3 and H9N2 viruses in the field, probably during co-infection of poultry. Based on the deduced amino acid sequences for the cleavage site of the haemagglutinin genes, it was concluded that the first H7N3 introduction of AIVs in 1995 was lowpathogenic, while a highly pathogenic virus emerged after circulating for 6-8 months in the poultry population.

Pakistan reported its first case of H5N1 in February 2006 in the north-west frontier province, now called Khyber Pakhtunkhwa. By June 2008, 51 outbreaks had been reported to the Office International des Epizooties (OIE), the World Organization for Animal Health, 39 on commercial farms and 12 among back- 
yard poultry, pet and wild birds. Out of 128 districts, the outbreaks occurred and re-occurred in eight districts, namely Karachi, Islamabad, Rawalpindi, Charsada, Swabi, Peshawar, Abbottabad and Mansehra. Considering the socioeconomic and public health impact of AIVs, a surveillance system was established which comprises of a country-wide network of 10 provincial and 40 regional (sub-provincial) laboratories.

H5N1 and other notifiable AIVs are one of the biggest risks for Pakistan's poultry industry as these viruses can completely disrupt poultry production as evidenced during the outbreak of 2003-2004. Early detection and effective management of an outbreak is critical for the government, the industry and the community. To make efficient use of limited resources, surveillance and preventive measures must be targeted at areas and populations at particularly high risk of infection. Wetlands are aggregation sites for migratory and resident wild birds and therefore constitute a potentially high risk for the introduction and transmission of AIVs (Hlinak et al., 2006; Jourdain et al., 2007; Martinez et al., 2009; Iglesias et al., 2010). Despite its arid climate, Pakistan supports more than 780,000 ha of wetlands that cover $9.7 \%$ of the total land area. There are 225 major wetlands, 19 of which are recognized as being of international importance by the Ramsar Convention ${ }^{1}$. Under Global 2002, the Earth has been divided into 238 ecoregions, out of which five are located in Pakistan (Fig. 1). The country lies across the central Asian flyway of migratory birds and towards its intersection with the West Asian - East African flyway. From the northern mountains to the southern coast, wetland areas provide wintering grounds for a large number of waterbirds coming from Siberia and the central Asian states (Sheikh and Kashif, 2006). The arrival of these birds starts in early September and continues until the end of October or mid - November. The birds follow the Indus flyway over the Karakorum, Hindu Kush and Suleiman mountain ranges, and finally along the Indus river to its delta near the Arabian Sea. After spending their

\footnotetext{
1 The Convention on Wetlands of International Importance, called the Ramsar Convention, is an intergovernmental treaty that provides the framework for national action and international cooperation for the conservation and wise use of wetlands and their resources. The Ramsar Convention is the only global environmental treaty that deals with a particular ecosystem. The treaty was adopted in the Iranian city of Ramsar in 1971 and the Convention's member countries cover all geographic regions of the planet.

2 The Global 200 is the list of ecoregions identified by the World Wildlife Fund (WWF) as priorities for conservation. According to the WWF, an ecoregion is defined as a "relatively large unit of land or water containing a characteristic set of natural communities that share a large majority of their species dynamics, and environmental conditions.
}

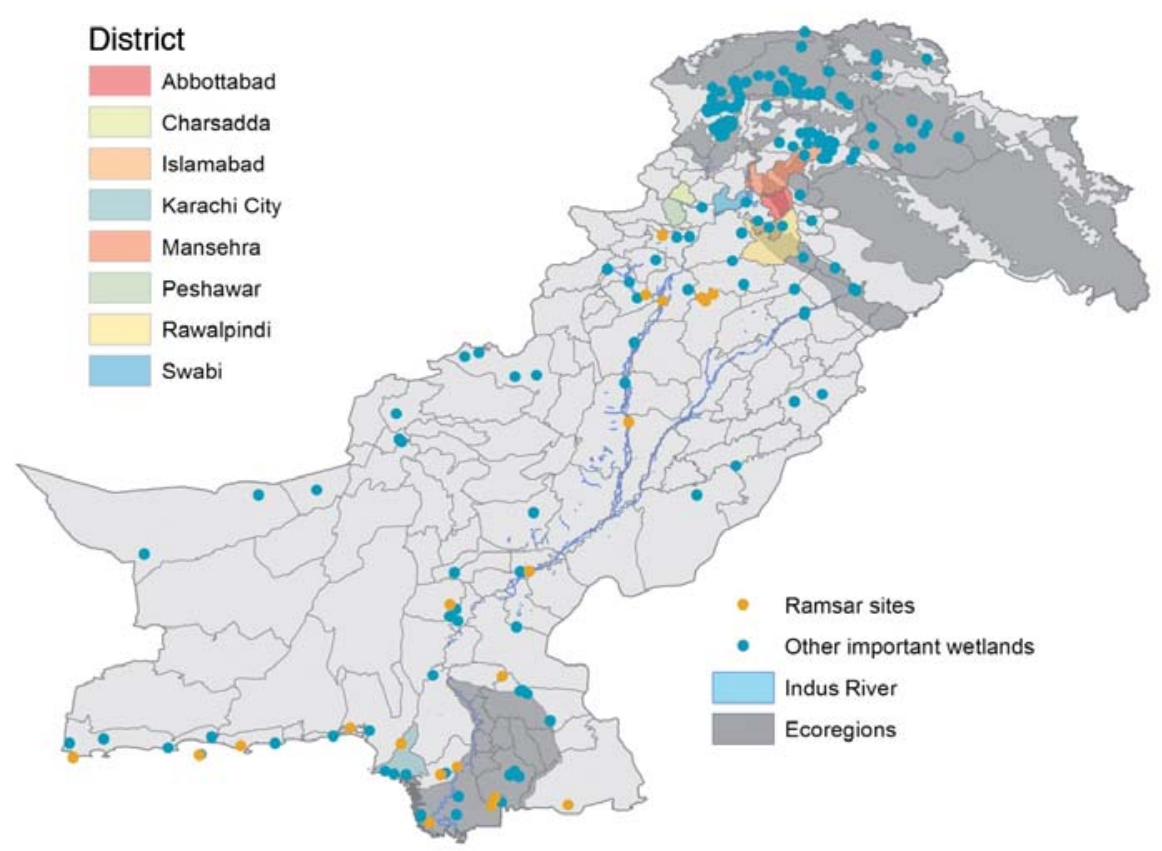

Fig. 1. Global 200 ecoregions and important wetlands in Pakistan, including the districts that reported H5N1 outbreaks in poultry between 2006 and 2008 . 
winter there, these birds migrate back to their breeding habitats during February to March (Malik, 2010). The objective of this study was to evaluate and map available information on wetlands and waterbird populations of the country. In addition, a framework was created to define priority areas for surveillance and prevention of AIVs during the migratory season.

\section{Materials and methods}

\section{Data sets}

The Asian waterbird census (AWC) is a regional programme promoting public participation to monitor the distribution and populations of water birds and the status of the wetlands. Through a large network of volunteers working through national coordinators, the census is normally organised the second and third weeks of January. The AWC sites represent all types of natural and man-made wetlands. All water bird groups encountered in the region as recognised by the Ramsar Convention are covered by the census (Li et al., 2009). The AWC data relevant to Pakistan were obtained from Wetlands International. The data contained the local names of 535 sites and for each site, the annual count of waterbirds from 1987-2007.

The poultry density raster used in the study was derived from the "Gridded Livestock of the World" database, which is freely available on the Food and Agriculture Organization of the United Nations (FAO) website (http://www.fao.org/geonetwork). The map represents the predicted poultry density at a resolution of three arc minutes (approximately $5 \mathrm{~km}$ ). Each pixel contains an estimated value for number of poultry per $\mathrm{km}^{2}$. For Pakistan, the estimation is based on the poultry population according to the agriculture statistics of 2006. The layer was developed by Robinson et al. (2007). In short, available national agriculture statistics on livestock populations were converted into densities and adjusted to account for the area of land deemed suitable for livestock production based on environmental, land-cover and land-use criteria. Robust statistical relationships between livestock densities and predictor variables were established. Modeling was used to predict livestock densities in areas for which no livestock data were available. Models were developed separately for different geographical regions and ecological zones.

Part of this study involved use of the shuttle radar topography mission (SRTM) water-body (vector shapefile) data representing lakes and rivers. These data were extracted from the ESRI software
(Redlands, CA, USA) on data and maps (2004). For analyses and interpretation of the findings, the shapefile of the districts, the second order administrative divisions of Pakistan, was downloaded from http://www.pakresponse.info, a website dealing with relief activities after flooding and other natural disasters in the country.

\section{Analytical framework}

The AWC data was managed using IBM $^{\circledR}$ SPSS 19 (SPSS Inc., Chicago, IL, USA). However, the birds were not counted regularly in the majority of the sites, leaving gaps in the sites-by-year data matrix (here called "missing values"), the patterns of which first had to be analysed. Moreover, Little's MCAR test was run to assess whether the distribution of missing values missing was random.

Information about coordinates was not available for 239 sites, which were therefore excluded from further analyses. The subset of data was displayed by XY coordinates in ArcGIS 10 (ESRI, Redlands, CA, USA). Sites with coordinates falling outside the boundaries of the country were also excluded $(\mathrm{n}=21)$.

The sites were divided into five classes using natural breaks classification (Jenks and Caspall 1971) to be able to create a map of maximum reported counts. The natural breaks classification algorithm was used because the data were skewed with the values distributed in multiple clusters and we needed to ensure internal homogeneity within classes while maintaining heterogeneity among them. The same classification scheme was used for reclassifying the poultry density layer. The reclassification process transformed raw cell values into values from 0 to 5 in the order of low to high density.

\section{Statistical analysis}

Since it should be interesting for national coordinators to visualise statistically significant local clusters of sites with a high number of missing values, a hot/cold spot analysis was carried out for the identification of the local clusters of under-sampled sites. For this purpose, the Getis-Ord Gi* statistic, a tool for indexing the spatial clustering of a set of observations over a defined neighbourhood (Petrucci and Salvati, 2006), was applied. Formally, the Getis-Ord Gi* statistic is defined as follows (Rogerson, 2010):

$$
G *=\frac{\sum_{j} w_{i j} x_{i j}-w_{i}^{*} \bar{X}}{s \sqrt{\left(n s_{l i}^{*}-w_{i}^{* 2}\right) /(n-1)}},
$$


where $n$ is the total number of features (sites) in the study area, $x$ the numeric variable associate with each feature (sum of unobserved/missing values from 19872007), $\bar{X}$. the mean of $x$ values and $s$ the standard deviation of the $x$ values. $w_{i j}$ is the spatial relationship between $i$ and $j$, given a value of one (1) if $i$ and $j$ are neighbours including $i$ itself (i.e. $w_{i i}=1$ ), and otherwise zero $(0)$.

$$
\begin{aligned}
& w_{i}^{*}=\sum_{i} w_{i, j} \\
& s_{l i}^{*}=\sum_{j} w_{i, j}^{2}
\end{aligned}
$$

Local Getis-Ord $\mathrm{Gi}^{*}$ returns a z-score indicating the degree to which a location is surrounded by locations with similar values. $Z$-score values near zero show no similarity in values. Statistically significant values at the $95 \%$ confidence level are those that fall outside the range -1.96 to +1.96 . A significant negative Getis-Ord $\mathrm{Gi}^{*} \mathrm{z}$-score indicates that that location is part of a low-value cluster (coldspot), whereas a significant positive Getis-Ord Gi* z-score indicates that the location is part of a high-value cluster (hotspot) (de Souza et al., 2010).

The ArcGIS spatial statistics tools require data in a projected coordinate system. The projection used in this analysis was Asia South Lambert Conformal Conic (Cima and Urbano, 2010). The variable of interest was the number of missing values per site. The K-nearest-neighbour approach (Kulldorf, 1998) was used as a method for conceptualisation of spatial relationships because (i) the density of sites was not the same across the country and (ii) the distribution of missing values was skewed. Eight was chosen as the number of nearest neighbours for each site. The GetisOrd $\mathrm{Gi}^{*}$ statistic is asymptotically normally distributed as the number of neighbours increases. For lightly skewed distributions of $x$, a number of eight neighbours or more is enough to ensure a sufficient approximation (Scrucca, 2005).

For the surveillance and prevention of AIVs during the migratory season, priority should be given to the poultry rearing areas closer to the wetlands. To map and predict the poultry density within such areas, buffer zones of 3,6 and $9 \mathrm{~km}$ radius were created around the (SRTM) water-bodies (Fig. 2). For each category of buffer zones, polygons containing coordinates of AWC sites were separated and called type A polygons (areas around known water-bodies with reported waterbird activity). Circular polygons of the same size as the buffer were also drawn around the coordinates falling out of the defined range. These were called type B polygons. The two types of polygons were combined through the "union" followed by "dissolve" functions of the software. The final output layer was used as a mask to detect the pixels of predicted poultry density.

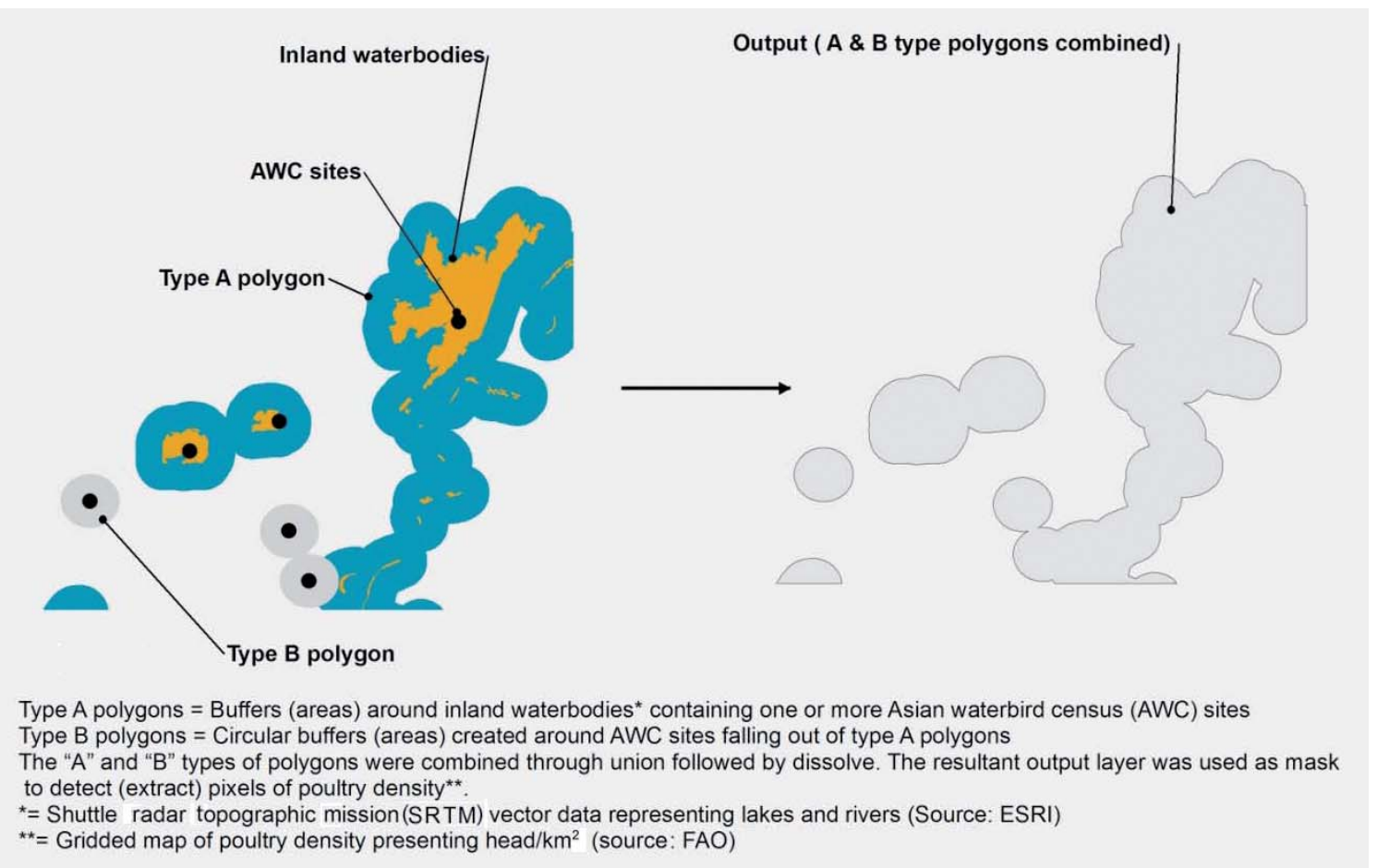

Fig. 2. Geoprocessing of AWC and SRTM data. 
A retrospective case-series analysis of $\mathrm{H} 5 \mathrm{~N} 1$ outbreaks in poultry was performed for outbreaks reported to OIE between 2006 and 2008. The first reported outbreak in a given area was treated as the index case and included in the study. Outbreaks occurring within a $3 \mathrm{~km}$ radius of the index case in a temporal window of 21 days were considered as secondary and therefore excluded. The proportion of outbreaks between the migratory and the non-migratory period was compared using the one-way chi-square test.

\section{Results}

The AWC data contained a substantial amount of missing values. The inclusion of all 535 sites over the 21-year period gave us 11,235 site-year combinations, 1,730 of which were fully observed $(15 \%)$, while 9,505 $(85 \%)$ were missing. The pattern of missing values was completely at random (Little's MCAR test: $\chi^{2}=912.0$; $\mathrm{df}=920 ; \mathrm{P}=0.57)$ and monotone. In Fig. 3 , the years have been ordered from left to right in increasing order of missing values. A dataset can potentially have $2^{n}$ patterns of missing values where $\mathrm{n}$ is the number of variables (SPSS, 2010). In the data under investigation, the number of variables (i.e. years) was 21 , and 151 patterns were observed. The most frequent pattern was 151 which represent the sites for which a count was reported only once during 1993.

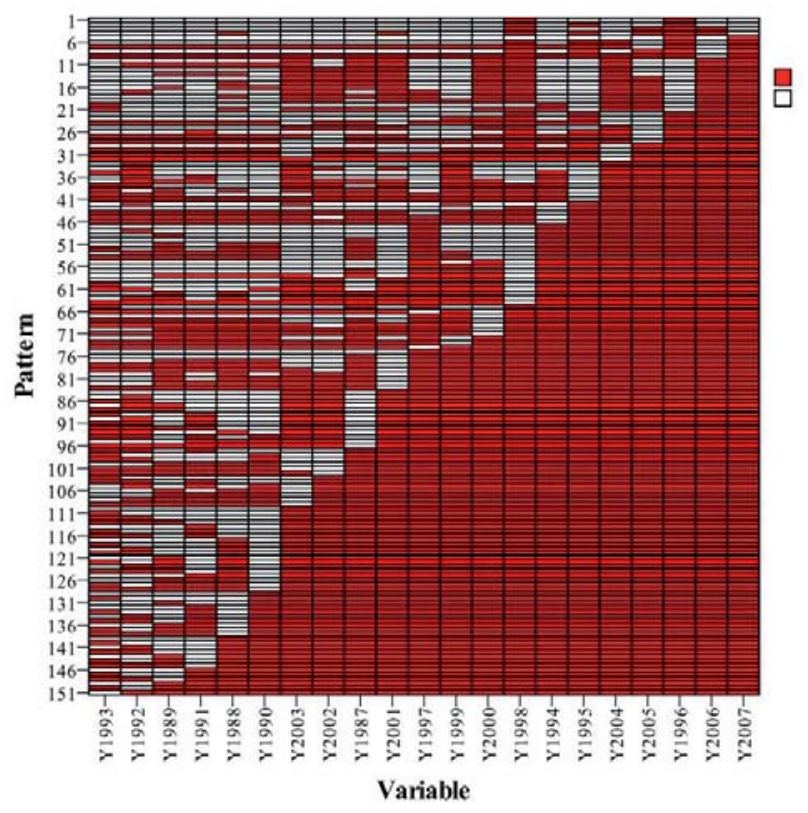

Fig. 3. Patterns of missing values in Asian waterbird census data 1987-2007.

The results of the analysis of missing values using the Getis-Ord Gi* statistic are shown in Fig. 4. The map illustrates statistically significant (at the 0.05 level) clusters of sites with high or low number of missing values. Clusters of sites with high values (hotspots, $\mathrm{n}=35$ ) were found exclusively in the Sindh province, whereas those with low values (coldspots,

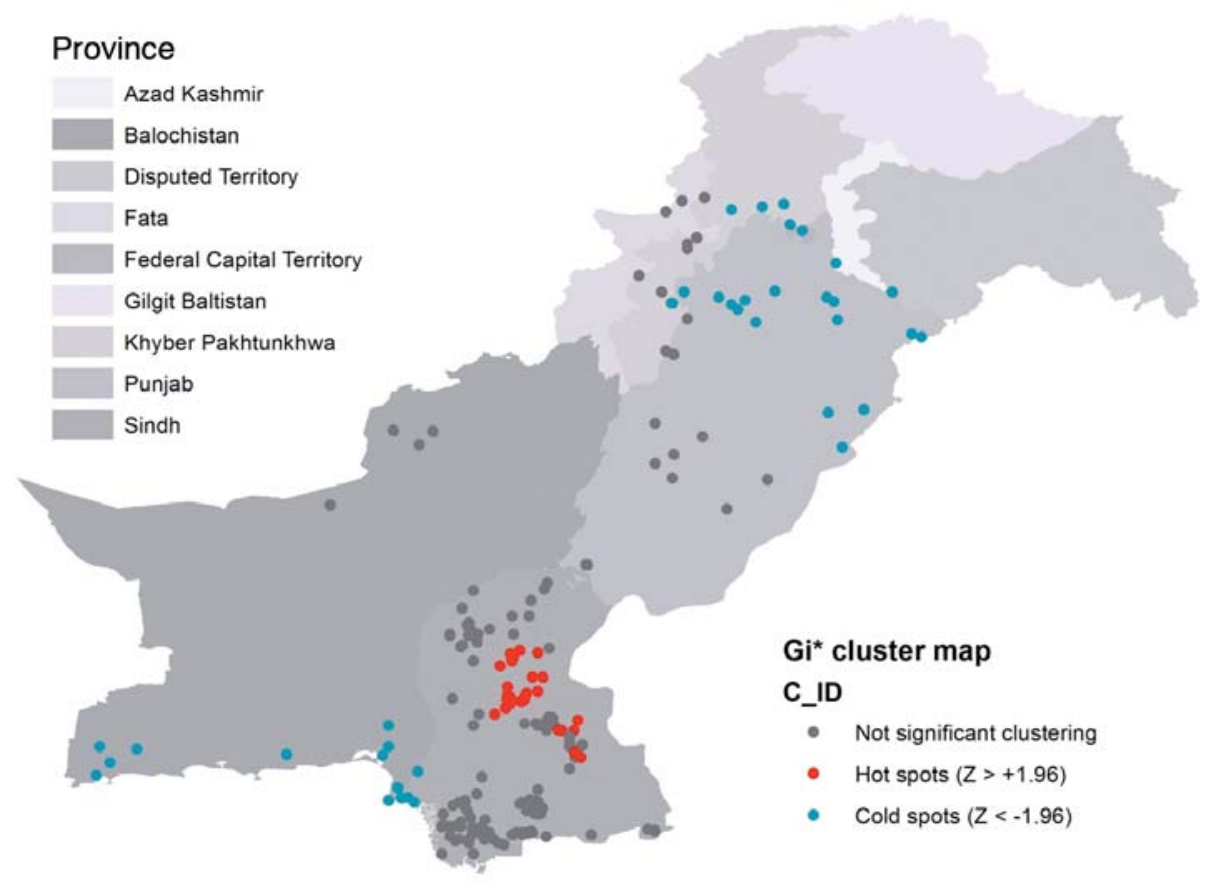

Fig. 4. Results of hotspot analysis of missing values per site during 1987-2007 ( $\mathrm{n}=270 / 535)$. The $\mathrm{z}$-scores $>1.96$ represent statistically significant hotspots, while those $<-1.96$ are statistically significant coldspots. The majority of sites fall in the statistically insignificant middle categories indicating absence of apparent clustering. 
$\mathrm{n}=37)$ were observed in Punjab, Baluchistan and Khyber Pakhtunkhtwa. Many $(\mathrm{n}=198)$ of the sites returned $z$-scores that suggested non-significant clustering. The mean number of missing values of sites categorised as hotspots and coldspots was 19.26 and 11.49 , respectively.

The AWC sites (coordinates) were located in 58 (out of 128) districts. The districts containing higher numbers of coordinates were Badin, Thatta and Sanghar, all of which in Sindh. The coordinates are assumed to provide a crude approximation of the distribution of waterbirds during the migratory season. There were 42 sites where the count was $\geq 26,000$. The coordinates of these sites were situated in the district Thatta, Shahdad Kot, Sanghar, Okara, Mushki, Mianwali, Layyah, Larkana, Lakki Marwat, Khairpur, Kashmore, Karachi, Jhelum, Jamshoro and Badin (Fig. 5).

A total of 137 out of 270 coordinates $(50 \%)$ fell within the $3 \mathrm{~km}$ range of SRTM water-bodies. The number of coordinates within the 6 and $9 \mathrm{~km}$ zones was 181 and 209, respectively. With a radius of $3 \mathrm{~km}$, the output layer (produced by combining type $\mathrm{A}$ and type B polygons) enclosed 1,007 pixels of predicted poultry density with reclassified values ranging from 0 to 3 . There were only 23 pixels $(2.23 \%)$ with a value equal to 3 . Those were found in the districts Charsada, Haripur, Jhelum, Gujrat, Kohat, Larkana, Nowshera and Shahdadkot. The values of pixels within the 6 and
$9 \mathrm{~km}$ buffers ranged from 0 to 4 . We did not observe any pixel with a value equal to 5 . As expected, the number of pixels increased with the size of the buffer, but the distribution of their values remained rightskewed (Fig. 6).

The retrospective case-series analysis of the $\mathrm{H} 5 \mathrm{~N} 1$ data revealed that 33 out of 51 outbreaks (64\%) occurred during the migratory season, 21 of which were primary outbreaks according to the defined study criteria. There was a statistically significant difference in the number of outbreaks during the migratory and the non-migratory period $\left(\chi^{2}=4.00 ; \mathrm{df}=1\right.$; $\mathrm{P}=0.04)$. Most outbreaks (32/33) occurred in districts that contained either at least one major wetland or were located in an ecoregion. These districts were Abbottabad, Rawalpindi, Islamabad, Karachi and Peshawar (Fig. 1).

\section{Discussion}

Aquatic wild birds are the natural reservoir of influenza A viruses (Webster et al., 2007). Experimental infection studies reveal that some wild ducks, geese and swans can even remain without symptoms and still shed the H5N1 virus, and hence have the potential to spread it as they move (Gaidet et al., 2010). The exact role of migratory wild birds in the epidemiology of H5N1 and other AIVs in Pakistan is still unknown. In addition, there is a dearth of infor-

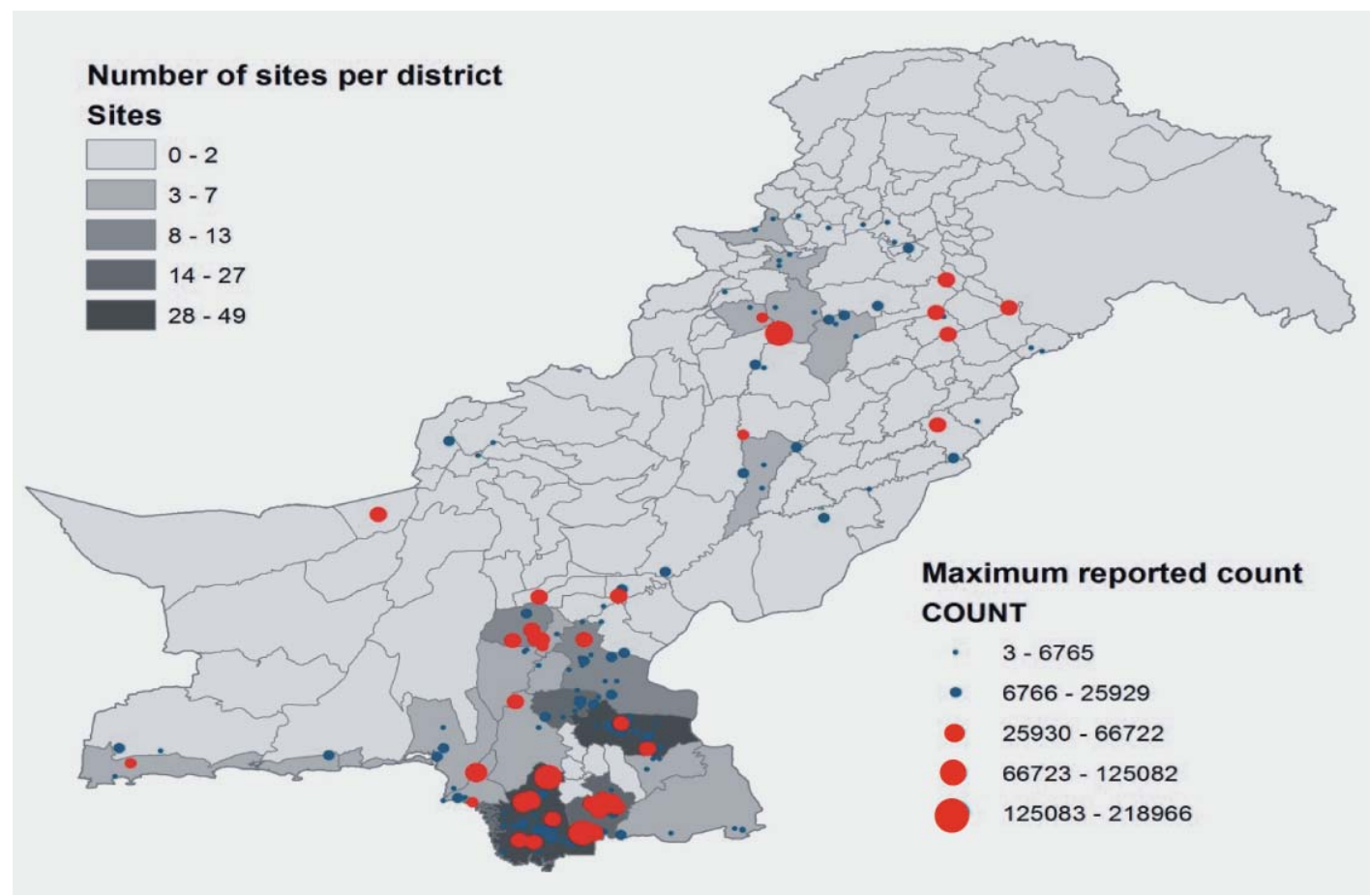

Fig. 5. Maximum counts per site reported during 1987-2007. The map was created using data from 270 out of 535 sites. The red spots are the sites with counts $\geq 26,000$ at least once during 1987-2007. 
mation on the routes of virus transmission between wild birds and poultry. Backyard poultry are usually free-range and therefore more vulnerable to contact with wild birds while foraging in cultivated fields (Cecchi et al., 2008). Moreover, the sale of infected village chickens in live bird markets may introduce the virus into the commercial poultry circuit. Possible mechanisms by which virus from infected waterfowl may enter a commercial poultry holding could be through the use of untreated surface water, the entry of bridge species into poultry sheds or access of wild birds to drinking water, feed or bedding material (FAO, 2008). Spillover of virus from poultry operations to wild birds may occur due to lapses in biosecurity such as disposal of carcasses of dead birds, manure, and other effluents into the environment (de Glanville et al., 2010). The interface between wild birds and poultry is a critical factor that can be controlled through biosecurity measures (Spackman, 2009). Creating awareness and the involvement of farmers in the surveillance and reporting of unusual bird mortalities should enhance early detection of the virus. In this study, a subset of AWC data was mapped and the attributes identified, which may be helpful in surveillance and prevention of AIVs in domestic poultry.

The analysis of AWC data revealed a high proportion of missing values. One of the reasons for this has been described as inconsistencies in annual coverage of many sites (Li et al., 2009). Clusters of sites with high missing values were found to be concentrated in Sindh province. This province contains wetland complexes such as the Nara canal and Rann of Kutch. Identified amongst the 40 biologically richest ecoregions in the world, the Indus ecoregion covers approximately $65 \%$ of Sindh occupying 18 districts. At some locations, groups of lakes are also present, e.g. the Nara canal area contains 200 small lakes, out of which only 16 are considered important for waterbirds (Rao, 2000). It is likely that many small lakes in Sindh were included in AWC but could not be regularly counted. Another factor influencing the missing value rate of a site may be its accessibility ( $\mathrm{Li}$ et al., 2009).

The counting of birds is subjected to observer bias and may have a long term trend. These sources of error must be considered while interpreting the map of maximum reported count. An attempt was made to impute the missing values using the Trends and Indices for Monitoring (TRIM) software, version 5.35 (http://www.ebcc.info). TRIM is currently the standard programme for analysis of count data obtained from bird monitoring schemes (Pannekoek and van Strien, 2001). It analyses time-series counts, using Poisson regression (or loglinear regression) and produces estimates of yearly indices and trends (Ter Braak et al., 1994). The imputed values were not mapped because the model fitness was poor, partially due to site heterogeneity (i.e. trends differences between sites). Many of the missing values in the data were
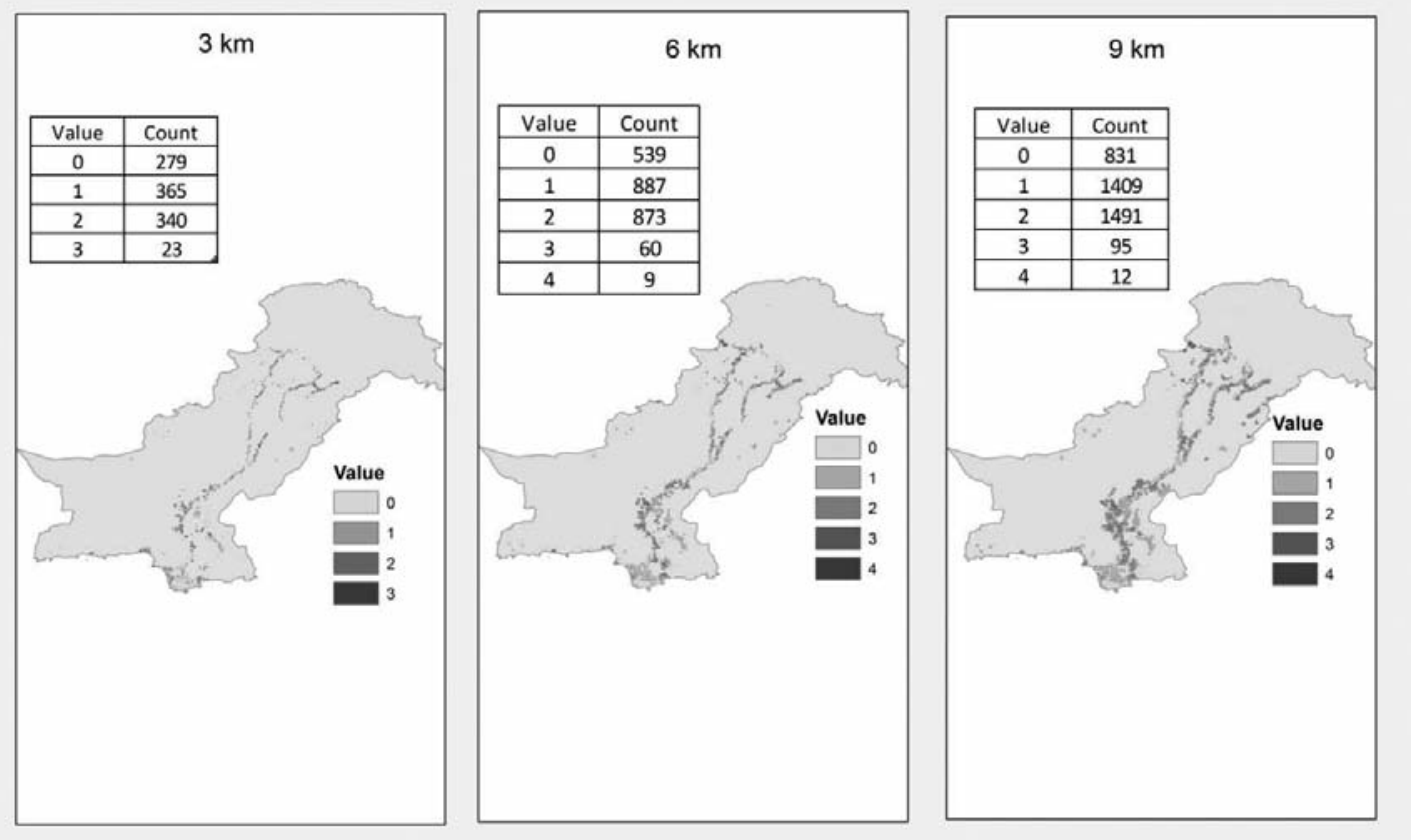

Fig. 6. Distribution of pixels of poultry density within 3, 6 and $9 \mathrm{~km}$ buffers created around AWC sites or water-bodies in their proximity. The maps contain pixels having a value from 0 to 3 or 0 to 4 in the order of low to high poultry density. No pixel with a value of 5 was detected. The embedded table shows the number of pixels (count) within each class (value). 
consecutive and could therefore not be replaced by moving average, mean (or median) of nearby points, interpolation or last observed carried forward. A linear trend model assumes a constant annual increase or decrease in counts. Such a model may be adequate for short-term series but becomes unrealistic if the time series is longer (Pannekoek and van Strien, 2001). The long-term (secular) trend in the data could not be confirmed; therefore we did not substitute the missing values by series mean. Over the last couple of decades, several methods have evolved for handling missing data. Some approaches are considered basic because they are conceptually straightforward and require minimal computations. Relatively new and complex techniques such as multiple imputation and expectation-maximization are also available in statistical software (Blankers et al., 2010) but their validity with this dataset would need further investigation.

When creating the maps, 275 sites had to be excluded because their coordinates were either unknown or fell outside the boundaries of the country. The average missing value rate of these sites was $95 \%$ which indicates rare waterbird activity events. Some districts, known to contain important wetlands ${ }^{3}$ but not presented in these maps, include: Chiral, Ghizer, Ghanche, Gilgit, Mansehra, Karak, Kashmore, Lakki Marwat, Killa Saifullah, Poonch, Swat and Zhob.

Mapping the geographic distribution of disease risk is a tool that may help decision makers to define highrisk areas and allocate resources accordingly. Priority areas for surveillance of highly pathogenic avian influenza $\mathrm{H} 5 \mathrm{~N} 1$ have been mapped in the United States (Miller et al., 2007), United Kingdom (Snow et al., 2007) and Australia (East et al., 2008). For Pakistan, such areas may be divided into two main categories:

(i) the poultry rearing areas located closer to major wetlands. Rawal Lake, for example, is an artificial reservoir that provides the water needs for the cities of Rawalpindi and Islamabad. According to an official source (Anonymous, 2004) there were approximately 170 poultry farms within the catchment area of the lake; and

(ii) the poultry rearing areas where surface water is used for drinking purpose. A major source of drinking water for the human, animal and poultry population of Karachi originates from water reservoirs including the Haleji Lake, the Hub dam, and the Kinjhar Lake. These water reserves

\footnotetext{
${ }^{3}$ Source: Pakistan wetlands programme, Ministry of Environment, (http://www. pakistanwetlands.org)
}

are internationally well known for the breeding, staging, and overwintering of migratory waterfowl (Anjum, 2004).

In this study, we compared the distribution of values of pixels of predicted poultry density at varying distances from AWC sites or nearby water-bodies. The choice of the buffer radii was partially based on the recommendations of the FAO (Anonymous, 2009) and can be further modified, e.g. based on expert opinion.

It is important to note that the poultry density layer used in this study was created using low-resolution data and may have omission and commission errors. Omission errors occur when a pixel is not assigned a value when, in fact, it should have been assigned. Commission errors occur when a pixel is assigned a value other than its true value (Baker, 2008). A high poultry density pixel should not be confused with an increased likelihood of infection. The characteristics of migratory birds populations can affect the likelihood of exposure such as gregariousness, degree of mixing with other species, contact risk with poultry, feeding habits (scavenging/predation) and the percentage of juveniles in the population (Caron et al., 2010). The current raster is limited by the fact that it does not show commercial and backyard poultry separately. The government has formulated a plan to register all commercial poultry farms in the country; therefore in future the current poultry density map can be improved or a layer of poultry farm density created at the level of the union councils, the fourth order of administrative boundaries of Pakistan.

The coordinates of 66 out of 270 eligible sites (25\%) fell at a distance of more than $9 \mathrm{~km}$ from SRTM water-bodies. The following considerations may offer possible explanations: (i) the coordinates of AWC sites may be inaccurate; (ii) the wetlands may have been degraded over the period of time; and (iii) there could be errors in SRTM data, e.g. misclassification of land into water-body.

Retrospective case-series analysis of H5N1 outbreaks confirmed significantly higher numbers of outbreaks during the migratory season. It is an interesting finding which may, or may not be, related to seasonality (Lofgren et al., 2007). Case-series generally provide weak evidence of causality because they are particularly prone to bias and confusion. Furthermore, the absence of a control group is a critical limitation (Ho et al., 2008). Results of case series can generate hypotheses that are useful in designing further studies. However, no causal inferences should be made from such studies (Kooistra et al., 2009). Prosser et al. (2011) studied the movements of bar-headed geese 
marked with satellite transmitters at Qinghai Lake in China. H5N1 outbreaks in domestic birds were found to spike in frequency when up to $50 \%$ of the global population of bar-headed geese overwintered in the sheltered river valleys surrounding Lhasa region.

This paper provides an overview of wetlands, waterbirds and their migration cycles in Pakistan, highlighting potential use and limitations of the AWC data in context to avian influenza. AWC sites and associated professionals may be a source of ornithological data. They may also be involved in active and passive surveillance of wild birds. Poultry rearing areas close to AWC sites or water-bodies as mapped in this study may be given priority to assess, communicate and manage the risk of transmission of AIVs between poultry and wild birds. There is a need to build up a geospatial database of major wetlands and of commercial poultry holdings in the country. We also recommend a survey on the adoption of biosecurity and a participatory disease surveillance programme in poultry rearing areas close to important wetlands. The hotspot analysis described can be useful for other countries of Asia to identify clusters of sites or regions neglected from annual mid-winter waterfowl counting; the Asian waterbird census.

\section{References}

Abbas MA, Spackman E, Swayne DE, Ahmed Z, Sarmento L, Siddique N, Naeem K, Hameed A Rehmani S, 2010. Sequence and phylogenetic analysis of $\mathrm{H} 7 \mathrm{~N} 3$ avian influenza viruses isolated from poultry in Pakistan 1995-2004. Virol J 7, 1-10.

Anjum AD, 2004. Possible role of migratory birds for introduction avain influenza in Pakistan. Available at: http://www.worldvet.org (accessed in December 2007).

Anonymous, 2004. Rawal lake catchment area monitoring operation. Pakistan Environmental Protection Agency, Ministry of Environment. Available at: www.environment. gov.pk/rawlDam-pdf/RwlLakMng.pdf (accessed in June 2010).

Anonymous, 2009. Biosecurity guideline for the commercial poultry industry in Bangladesh. Department of Livestock Services (DLS), Bangladesh. Available at: http://www. aitubd.org/ (accessed in November 2010).

Baker MN, 2008. Identifying focal wildlife conservation areas on private lands in North Carolina. MSc thesis. Duke University, Durham, North Carolina. http://dukespace.lib.duke.edu/ dspace/handle/10161/501 (accessed in October 2008).

Blankers M, Koeter MW, Schippers GM, 2010. Missing data approaches in eHealth research: simulation study and a tutorial for nonmathematically inclined researchers. J Med Internet Res 12, e54.
Caron A, de Garine-Wichatitsky M, Gaidet N, Chiweshe N, Cumming GS, 2010. Estimating dynamic risk factors for pathogen transmission using community-level bird census data at the wildlife/domestic interface. Ecol Soc 15, e25.

Cecchi G, Ilemobade A, Le Brun Y, Hogerwerf L, Slingenbergh J, 2008. Agro-ecological features of the introduction and spread of the highly pathogenic avian influenza (HPAI) H5N1 in northern Nigeria. Geospat Health 3, 7-16.

Cima R, Urbano F, 2010. Selection of suitable areas for olive growing in Pakistan. Istituto Agronomico per l'Oltremare. Available at: www.oliveoilpakistan.com/.../olive_oil_pakistan_monographs_light.pdf (accessed in December 2010).

de Glanville W, Idris S, Costard S, Unger F, Pfeiffer D, 2010. A quantitative risk assessment for the onward transmission of highly pathogenic avian influenza H5N1 from an infected small-scale broiler farm in Bogor, West Java, Indonesia. Available at: http://www.ifpri.org/sites/default/files/publications/hpaiwp23_indonesia.pdf (accessed in September 2011). de Souza D, Kelly-Hope L, Lawson B, Wilson M, Boakye D, 2010. Environmental factors associated with the distribution of Anopheles gambiae in Ghana; an important vector of lymphatic filariasis and malaria. PLoS One 5, e9927.

East IJ, Hamilton S, Garner G, 2008. Identifying areas of Australia at risk of $\mathrm{H} 5 \mathrm{~N} 1$ avian influenza infection from exposure to migratory birds: a spatial analysis. Geospat Health 2, 203-213.

FAO, 2008. Biosecurity for highly pathogenic avian influenza issues and options. Available at: ftp://ftp.fao.org/docrep /fao/011/i0359e/i0359e00.pdf (accessed in August 2010).

Gaidet N, Cappelle J, Takekawa JY, Prosser DJ, Iverson SA, Douglas DC, Perry WM, Mundkur, T, Newman SH, 2010. Potential spread of highly pathogenic avian influenza H5N1 by wildfowl: dispersal ranges and rates determined from largescale satellite telemetry. J Appl Ecol 47, 1147-1157.

Hlinak A, Muhle RU, Werner O, Globig A, Starick E, Schirrmeier H, Hoffmann B, Engelhardt A, Hubner D, Conraths FJ, Wallschlager D, Kruckenberg H, Muller T, 2006. A virological survey in migrating waders and other waterfowl in one of the most important resting sites of Germany. J Vet Med B Infect Dis 53, 105-110.

Ho PM, Peterson PN, Masoudi FA, 2008. Evaluating the evidence: is there a rigid hierarchy? Circulation 118, 1675-1684. Iglesias I, Jesus MM, Martinez M, de la Torre A., 2010. Environmental risk factors associated with H5N1 HPAI in Ramsar wetlands of Europe. Avian Dis 54, 814-820.

Jenks FG, Caspall FC, 1971. Errors on choroplethic maps: definition, measurment, reduction. Annals of the AAG 61, 217244.

Jourdain E, Gauthier-Clerc M, Bicout DJ, Sabatier P, 2007. Bird migration routes and risk for pathogen dispersion into western Mediterranean wetlands. Emerg Infect Dis 13, 365-372.

Kooistra B, Dijkman B, Einhorn TA, Bhandari M, 2009. How 
to design a good case series. J Bone Joint Surg Am 91, 21-26.

Kulldorff M, 1998. Statistical methods for spatial epidemiology: tests for randomness. In: Gatrell AC, Löytönen M (eds). GIS and Health, Taylor \& Francis, London, UK, pp. 49-62.

Li ZWD, Bloem A, Delany S, Martakis G Quintero JO, 2009. Status of waterbirds in Asia: results of Asian waterbird census: 1987-2007. Wetlands International, Kuala Lumpur, Malaysia.

Lofgren E, Fefferman NH, Naumov JN, Gorski J, Naumova EN, 2007. Influenza seasonality: underlying causes and modeling theories. J Virol 81, 5429-5436.

Malik N, 2010. Documentary: Waterfowl in Pakistan. Available at: http://www.youtube.com/watch?v=WbT61Oz8waE (accessed in January, 2011).

Martinez M, Munoz MJ, de la Torre A, Iglesias I, Peris S, Infante O, Sanchez-Vizcaino JM, 2009. Risk of introduction of H5N1 HPAI from Europe to Spain by wild water birds in autumn. Transbound Emerg Dis 56, 86-98.

Miller RS, Farnsworth M, Kendall W, Doherty P, Nichols J, White G, Burnham K, Franklin A Freier J, 2007. Risk-based targeted surveillance: Identifying areas and populations of importance for surveillance of highly pathogenic avian influenza in the United States. In: Proceedings of the GIS vet conference, Copenhagen, Denmark.

Naeem K, Hussain M, 1995. An outbreak of avian influenza in poultry in Pakistan. Vet Rec 137, 439.

Naeem K, Siddique N, 2006. Use of strategic vaccination for the control of avian influenza in Pakistan. Dev Biol (Basel) 124, 145-150.

Naeem K, Siddique N, Ayaz, M, Jalalee MA, 2007. Avian influenza in Pakistan: outbreaks of low- and high-pathogenicity avian influenza in Pakistan during 2003-2006. Avian Dis 51, 189-193.

Naeem K, Ullah A, Manvell RJ, Alexander DJ, 1999. Avian influenza A subtype H9N2 in poultry in Pakistan. Vet Rec $145,560$.

NARC, 2009. Annual report 2008-2009. Pakistan Agriculture Research Council (PARC). Available at: www.parc.gov.pk/ AR/Ar-0809 (accessed in September 2010).

Nikolakopoulos KG, Kamaratakis EK, Chrysoulakis N. 2006. SRTM vs ASTER elevation products. Comparison for two regions in Crete, Greece. Int J Remote Sensing 27, 21.

Onkundi D, Bett B, Omore A, Costard S, 2008. Risk assessment activity in Kenya. Available at: www.dfid. gov.uk/r4d/PDF/Outputs/HPAI/WKS081002_Report.pdf (accessed in Sepember 2010).
Pannekoek J, van Strien AJ, 2001. Trends and indices for monitoring data (TRIM) manual. Available at: http:// www. cbs.nl/en-GB/menu/themas/natuur-milieu/methoden/trim/ default.htm (accessed in June 2010).

Petrucci A, Salvati N, 2006. Small area estimation for spatial correlation in watershed erosion assessment. J Agr Biol Envoron Stat 1, 169-182.

Prosser DJ, Cui P, Takekawa YJ, Tang M, Hou Y, Collins BM, Yan B, Hill NJ, Li T, Li Y, Lei F, Guo S, Xing Z, He Y, Zhou Y, Douglas DC, Perry WM, Newman SH, 2011. Wild bird migration across the Qinghai-Tibetan plateau: a transmission route for highly pathogenic H5N1. PLoS One 6, e17622.

Rao AL, 2000. Pakistan. Available at: www.ramsar. wetlands.org/Portals/15/Pakistan.pdf (accessed in March 2008).

Robinson TP, Franceschini G, Wint W, 2007. The Food and Agriculture Organization's gridded livestock of the world. Vet Ital 43, 745-751.

Rogerson PA, 2010. Statistical methods for geography- a student's guide, Sage Publications Ltd; pp. 257-278.

Scrucca L, 2005. Clustering multivariate spatial data based on local measures of spatial autocorrelation. Available at: http://econpapers.repec.org/RePEc:pia:wpaper:20/2005 (accessed in June 2011).

Sheikh KM, Kashif N, 2006. Strategic role of Pakistan wetland resources: prospects for an effective migratory waterbird conservation network. In: Boere GC, Galbraith CA, Stroud DA (eds.). Waterbirds around the world. The Stationary Office, Edinburgh, UK, pp. 292-293.

Snow LC, Newson SE, Musgrove AJ, Cranswick PA, Crick HQ, Wilesmith JW, 2007. Risk-based surveillance for H5N1 avian influenza virus in wild birds in Great Britain. Vet Rec 161, 775-781.

Spackman E, 2009. The ecology of avian influenza virus in wild birds: what does this mean for poultry? Poult Sci 88, 847-850.

Ter Braak CJF, van Strien AJ, Meijer R, Verstrael TJ, 1994. Analysis of monitoring data with many missing values : which method ? In Haemeijer EJM, Verstrael TJ (eds.) Proceedings of the bird numbers 1992. Distribution, monitoring and ecological aspects. Proceeding of the 12th International Conference of IBBC and EOAC, Statistics Netherlands, Voorburg/Heerlen \& SOVON, 1994, pp. 663-673.

Webster RG, Krauss S, Hulse-Post D, Ramirez KS, 2007. Evolution of influenza viruses in wild birds. J Wildlife Dis 43, 1-6. 